\title{
HISTOPATHOLOGY OF SOME DISEASED FISHES
}

\author{
M. Kabil Hossain, M. Delwar Hossain ${ }^{1}$ and M. Habibur Rahman ${ }^{2}$ \\ Institute of Biological Sciences, University of Rajshahi, Rajshahi-6205 \\ ${ }^{1}$ Department of Fisheries, University of Rajshahi, Rajshahi 6205, Bangladesh \\ ${ }^{2}$ Department of Zoology, University of Rajshahi, Rajshahi 6205, Bangladesh
}

\begin{abstract}
A study on the histopathology of some diseased fishes was carried out during the period from July 2005 to June 2006 in the Institute of Biological Sciences, University of Rajshahi, Rajshahi. Symptoms of diseases of different fish species showed variation among the species and its distribution. The parasites were first found to settled on the body surface and tip of the gills of fishes and attach themselves on the surface by their powerful sucking devices. From the histopathological observations it appeared that gills and body surface were the main infested areas and gill filaments were damaged by the parasites. The histochemical studies showed that the disease caused extensive damages to the blood elements by rupturing blood capillaries, causing necrosis, coagulation and haemorrhage.
\end{abstract}

Key words: Histopathology, symptoms, diseased fish

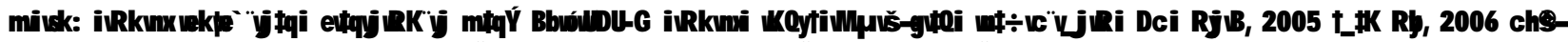

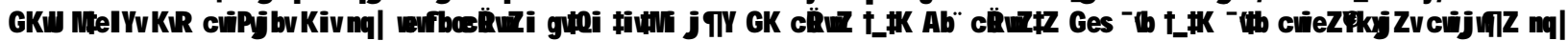

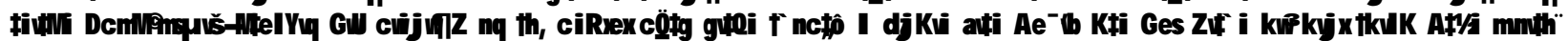

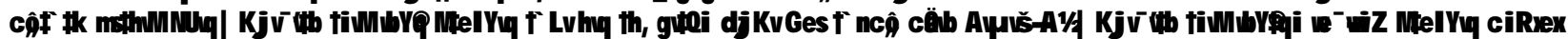

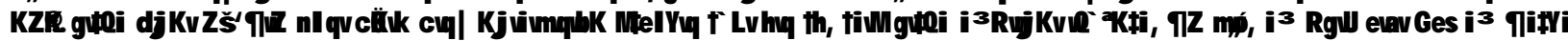
gla"łg i $\ddagger^{3}$ i DCv v

\section{Introduction}

The symptoms of the infected fishes are apparently not so visible with the external feature or free-living movement of fish. The examination begins with external observation of any fish suspected of having a disease. These pathogens obtain food by breaking down body tissues or by absorbing digested food from the intestines. In the gills hyperplasia takes place between the gill lamellae. The parasites feed on the newly produced cells and damage gill tissue (Makenzie and Hall 1976).

Usually in histopathology, the test is applied with tissue sections. However, the tissue is fixed for subsequent test. At the present time hematological investigations have been ever increasing in importance in practical fish pathology. Usually any hematological study is based upon the examination of smear, although hemoglobin and total protein estimations, serum electrophoresis and other biochemical determinations are also carried out. The blood undergoes serious changes, especially in the case of bacterial infections, but feeding and starvation also affect its composition such as total protein level, hemoglobin, and number of erythrocytes (Tonguthai, 1993).

Histopathology is an important diseases diagnostic tool. Ahmed and Hoque (1999) worked on histopathology of EUS affected fresh water fishes of Bangladesh. Ahmd et al. (2000) studied on catfish diseases in Mymensingh through histopathological techniques. The present investigation was aimed at the identification of fish diseases through clinical, parasitological, histopathological and histochemical observations of some diseased fishes.

\section{Materials and Methods}

In order to detect the presence of areas of trauma, ulcers, abscesses, loss of color and parasites, attention was paid to the natural openings and to the skin. For external appearance or autopsy of diseased fishes, the mouth, nasal orifices, head and opercula were observed with naked eyes and magnifying glass for deformities or moldy places. Diseased fishes were collected from local fish markets and were brought to the laboratory. This study was conducted from July 2005 to June 2006 in the Institute of Biological Sciences, University of Rajshahi.

\section{Preparation of histological slides}

After dissecting diseased fish tissues, the samples were quickly washed with physiological saline solution $(0.75 \% \mathrm{NaCl})$ and immediately fixed in $10 \%$ formalin. The following protocol was maintained for preparing histological slides.

Dehydration: The fixed tissues were gradually dehydrated in upgrading concentration of alcohol with $50 \%, 70 \%, 90 \%$ and $100 \%$ in $15 \mathrm{~min}, 45 \mathrm{~min}, 15 \mathrm{~min}$ and 15 min respectively. After dehydration the tissues were cleared in xylene for $10 \mathrm{~min}$.

Paraffin impregnation: The function of paraffin impregnation was to provide a hard supported block for sectioning. A paraffin bath with $60^{\circ} \mathrm{C}$ was used. The melting point of the paraffin was $54-58^{\circ} \mathrm{C}$. The tissues were treated in molten paraffin for $30 \mathrm{~min}-1 \mathrm{hr}$. 
Paraffin embedding: Metallic moulds and various types of containers including ice-cube trays and watch glasses were used for this purpose.

Blocking out of impregnated tissues: Molten wax was poured into the mould for solidification. With heated forceps the tissue was transferred and orientated so that the face to be cut was firmly embedded in the solidifying layer. When a thin layer was hardened on the outer surface the mould was quickly submerged in cold water. When completely solidified the block was removed from the mould.

Trimming and Sectioning: The blocks were then trimmed properly to the size of the tissue by cutting off the extra paraffin around the tissue. After trimming the blocks were kept in the ice chamber for a while before cutting the section. The block was fitted to the microtome for sectioning. Sections were cut on a microtome (BRIGHTNo. 5030) fitted with a sharpened microtome knife. The temperature of the water bath was maintained between $55-56^{\circ} \mathrm{C}$ for stretching the cut out ribbons. Blocks of fish tissues were cut at 6-8 $\mu$ in thickness.

Affixing and deparaffinization: The ribbons were attached on the glass slides by means of Mayer's albumen. In 20cc distilled water, 3-5 drops of Mayer's albumen was added, shook and then allowed to dry at $25^{\circ} \mathrm{C}-34^{\circ} \mathrm{C}$. The slides with ribbons containing tissues were kept at $60^{\circ} \mathrm{C}$ for ten min for melting, followed by immersing the slides in xylene I and xylene II for ten min each to remove the paraffin.

Rehydration of the tissues: The slides with tissues were then transferred to the following grades of alcohols: $100 \%$ for $10 \mathrm{~min}, 90 \%$ for $5 \mathrm{~min}, 70 \%$ for $5 \mathrm{~min}$ and $50 \%$ for $5 \mathrm{~min}$. At the end of this process tap water was used to remove alcohol.

Staining: The slides were then dipped in haematoxyline for $5 \mathrm{~min}$. Then they were washed properly with running water. They were then dipped in $0.5 \%$ alcohol for $30 \mathrm{sec}$ and washed again with running water. Finally they were dipped in eosin for1-2 min.

Dehydration and cleaning: The slides were then dehydrated gradually keeping in alcohol in the following way: in $70 \%$ for $5 \mathrm{~min}, 90 \%$ for 3-5 min and $100 \%$ for $15 \mathrm{~min}$. The stained tissues were finally cleaned in xylene for $10 \mathrm{~min}$.

Mounting and labeling: The permanent mounting of the slides was made by DPX and were labelled according to samples.

\section{Results and Discussion}

In the gills, hyperplasia takes place between the gill lamellae. The parasites feed on the newly produced cells and damage gill tissues. A large number of dead cell fragments attached with slime are found around them. They feed on the dead cells and gradually bore into the gill lamellae, thus creating a passage or holes, which perforate the blood vessels (Fig. 1-6). The gill epithelium is completely destroyed leaving large denuded areas among the filaments. The perforated basement membrane and capillaries cause bleeding. This condition disturbs respiration. Eventually the fish die of suffocation. It was observed from the histological sections that the infected epithelium showed epithelial hyperplasia. The epithelial cells must be locally irritated by the suction of the parasite, thus causing epithelial cellular growth and excess of mucus production. Parasite creates a favourable condition for them and finally leading to the death of the fish. Dactylogyrus was observed in skin and gills of fish. However parasitic infestations were more in the skin and muscles. Severity of infections and injury like haemorrhage, necrotic skin were increased and seen in dorso-ventral and caudal regions of the fishes. Deep necrosis turned into ulcers and extended up to tail regions in the diseased fishes.

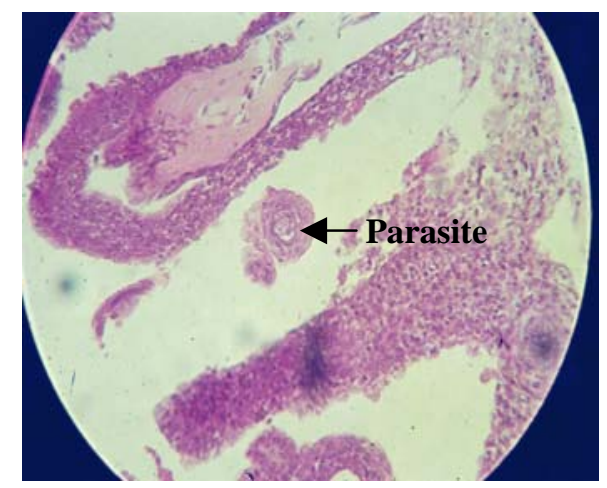

Fig. 1. Chilodonella cyprini found in gill of Catla catla

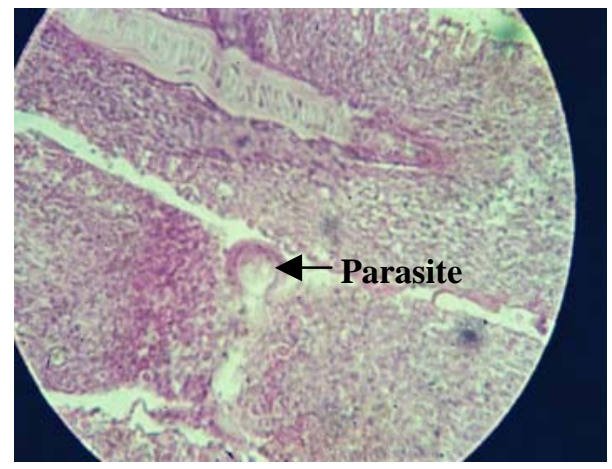

Fig. 2. Myxosoma cerebralis found in gill of Cirrhina mrigala 


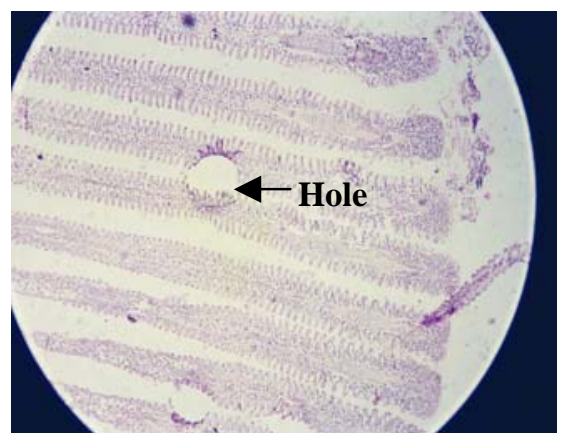

Fig. 3. Gill necrosis of Hypophthalmichthys molitrix due to parasitic attack

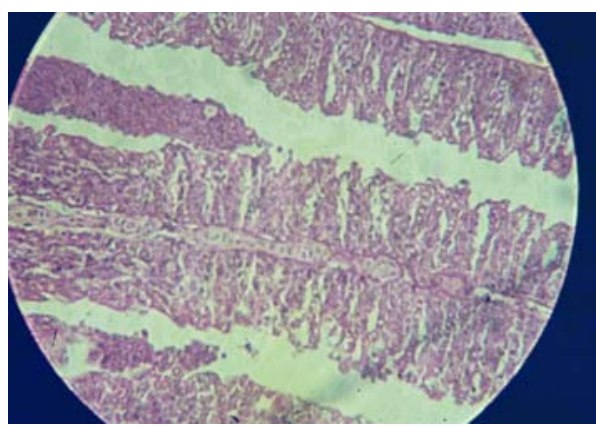

Fig. 4. Parasite damaged the gill filament of Labeo rohita

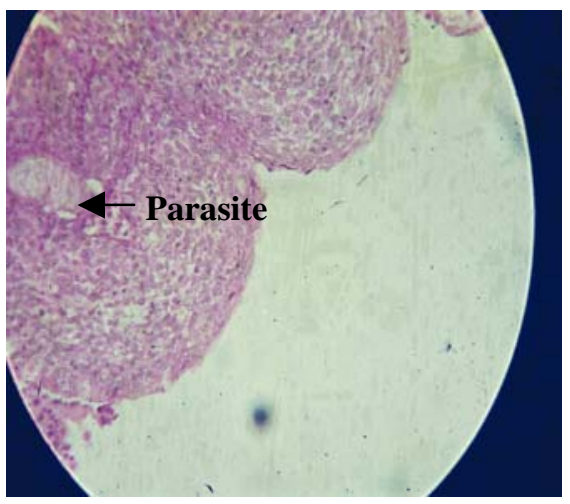

Fig. 5. Dactylogyrus sp. in gill of Cyprinus carpio

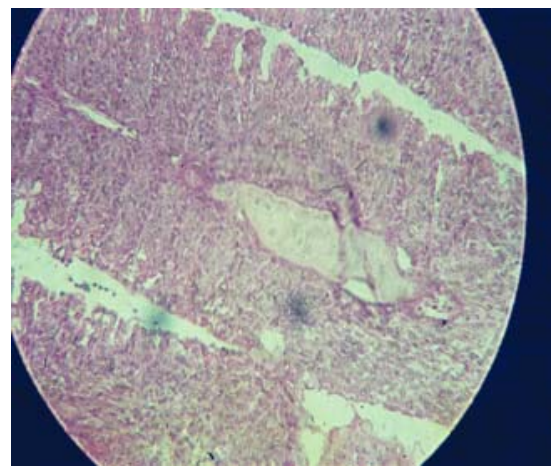

Fig. 6. Parasite damaged the gill of Labeo bata
Histopathological observations revealed that the gill filaments were damaged. Blood elements and plasma of dropsied and healthy carps were examined histochemically. The elements were varied in number and in quantities among the healthy and dropsied carp. Number of erythrocytes was found $1-45000 / \mathrm{cmm}$ in healthy carps and 22-850,000/cmm in dropsied carps. In healthy carps the number of granulocytes (75$90,000 / \mathrm{cmm}$ ) and the percentages of lymphocytes (89), granulocytes (11) and haemoglobin (9.6) were recorded. In the dropsied carps, these values were 90$135,000 / \mathrm{cmm}, 58 \%, 12-48 \%$ and $2-5.3 \%$ respectively (Table 1). In healthy carps, total albumin was 1.9$3.95 \mathrm{gm} \%$, globulin 1.48-1.98\%, cholesterol 32.6$204 \mathrm{mg} \%$, uric acid $0.56-2.64 \mathrm{mg} \%$ and glucose $40-$ 90mg\%. These were $0.4-2.75 \mathrm{gm} \%, 0.23-0.49 \%$, 15.6$98 \mathrm{mg} \%, 0.83-3.1 \mathrm{mg} \%$ and $14-53 \mathrm{mg} \%$ respectively in the dropsied carps (Table 2).

Table1. A comparison of blood elements between healthy and dropsied carps

\begin{tabular}{ccc}
\hline Blood composition & Healthy carps & Dropsied carps \\
\hline Number of erythrocytes & $1-450,000 / \mathrm{cmm}$ & $22-850,000 / \mathrm{cmm}$ \\
Number of & $75-90,000 / \mathrm{cmm}$ & $90-135,000 / \mathrm{cmm}$ \\
granulocytes & & \\
Erythrocyte: & $17-20: 1$ & $8-15: 1$ \\
granulocyte ratio & & \\
Lymphocytes & $89 \%$ & $58 \%$ \\
Granulocytes & $11 \%$ & $12-48 \%$ \\
Degenerated & - & $0-24 \%$ \\
granulocytes & & \\
Haemoglobin & $9.6 \%$ & $2-5.3 \mathrm{gm} \%$ \\
\hline
\end{tabular}

Table 2. A comparison of blood plasma between healthy and dropsied carps

\begin{tabular}{c|c|c}
\hline Blood composition & Healthy carps & Dropsied carps \\
\hline Total albumin & $1.9-3.95 \mathrm{gm} \%$ & $0.4-2.75 \mathrm{gm} \%$ \\
Globulin & $1.48-1.98 \%$ & $0.23-0.49 \%$ \\
Total cholesterol & $32.6-204 \mathrm{mg} \%$ & $15.6-98 \mathrm{mg} \%$ \\
Uric acid & $0.56-2.64 \mathrm{mg} \%$ & $0.83-3.1 \mathrm{mg} \%$ \\
Glucose & $40-90 \mathrm{mg} \%$ & $14-53 \mathrm{mg} \%$ \\
\hline
\end{tabular}

The erythrocytes of dropsied carp are progressively destroyed, and the leucocytes increase in number almost $50 \%$ above the normal figure. In abdominal dropsy the blood is also affected. The haemoglobin is reduced, and the blood undergoes morphological change, with destruction and disintegration of the erythrocytes. The granulocytes show characteristic vacuolization in the nucleus and cytoplasm. Mekenzie and Hall (1976) identified mycotic granulomas in histological sections of the red spot disease (RSD) affected fish during the initial outbreaks in Australia. Tonguthai (1993) observed needle-sized haemorrhages in Thai catfish. Ahmed and Hoque (1999) observed necrotic skin and muscle, dermal splitting and vacuolation in various carp 
species in Bangladesh. The present histological observations agreed with the findings on EUS of freshwater of South and Southeast Asia (Roberts et al. 1992; 1993) and on red spot disease of brackish water fishes of Australia (Callinan et al. 1989. Hatai et al. (1994) reported fungal hyphae and many granulomas in the internal organs and musculature of Colisa lalia suffering from an invasive mycosis in Japan. Ahmed et al. (2000) mentioned that EUS was prevalent in the catfish of Kailla Beel, Mymensingh.

In the present study Chilodonella cyprini and Myxobolus koi were found to infect the fish gills. The fish cells responded to the parasites with the abnormal production of mucus and protective reaction of epithetical hyperplasia. Ahmed (1976) reported that T. reticulata caused Trichodiniasis in carps in Japan created a sensation among fish farmer by causing considerable damage and mortality. Myxobolus in gill cause respiratory dysfunction and necrosis of gill leading to death (Kabata 1985). Physical presence of Trichodina and Myxobolus damage gills, obstruct blood circulation and open the portal entry for secondary infection and cause high mortality in the nursery operation system in carps (Subashinghe 1992). In the ulcerative form cutaneous and muscular changes are observed; the blood vessels break after an initial capillary hyperemia; the erythrocytes are released into the surrounding connective tissue, and the serous fluid liberated in this process penetrates the epidermis under pressure and produce lesions therein. The fluid of this edema contains serous components and isolated erythrocytes. The leucocytes, isolated or in groups, are rather more abundant. The ulcers produced in fresh water red pest contain a serous liquid with atrophied leucocytes and erythrocytes. A section through the ulcer reveals a hollow space situated in a zone limited by the hypodermic connective tissue and the dermis. The dermis shows intense haemorrhage in the proximity of the ulcers, for which reason these are seen macroscopically as having a red border. The present results would help identifying fish diseases and their causative agents for launching preventing measures against the pathogens.

\section{References}

Ahmed ATA, Sanaullah M. 1976. Organal and percentage distribution of some metazoan parasites in Heteropneustes fossilis (Bloch) and Clarias batrachus (L) J Asiat Soc Bangladesh 2(1), 7-15.

Ahmed GU, Hoque, MA. 1999. Mycotic involvement in epizootic ulcerative syndrome of fresh water fishes of Bangladesh: A histopathological study. Asian Fish Sci Philippines 12, 381-390.

Ahmed GU, Nessa M, Hoque MA, Ruksana, A, Khatun A. 2000. Investigation of catfish diseases in Mymensingh area through histopathological techniques. Bangladesh J Fish 23(1), 45-55.

Callinan RB, Keep JA. 1989. Bacteriology and parasitology of red spot disease in sea mullet, Mugil cephalus L., from eastern Australia. J Fish Dis 12, 349-356.

Hatai K, Nakamura K, Yuasa K, Wada S. 1994. Aphanomyces infection in Colisa lalia. Fish Pathol 29(2), 95-99.

Kabata Z. 1985. Parasites and Diseases of Fish Cultured in the Tropics. Taylor and Francis, London.

McKenzie RA, Hall WTK. 1976. Dermal ulceration of mullet (Mugil cephalus). Australian Vet J 52, 230-231.

Roberts RJ, Willoughby LG, Chinabut S, Tonguthai K. 1993. Mycotic Aspects of Epizootic Ulcerative Syndrome (EUS) in Asian Fishes. J Fish Dis 16, 169-183.

Roberts RJ, Ferichs N, Millar SD. 1992. Epizootic ulcerative syndrome the current position. In: Diseases Asian Aquaculture eds. IM Shariff, RP Subasinghe, JR Arthur. pp. 431-436. Fish Health section, Asian Fish. Soc., Manila

Subashinghe RP. 1992. Hatchery diseases of fresh water fish in Srilanka. In: Diseases in Asian Aquaculture eds IM Shariff, RP Subashinghe, JRArthur. Asian Fisheries Society. Philippines.

Tonguthai K, Chinabut S, Limsuwan C, Somsiri T, Chaniratchakool P, Kanchanakhan S, Mac Rae LH. 1993. Handbook of Hybrid catfish: Husbandry and Health. AAHRI. Thailand. pp 11-27. 